\title{
Revisão:
}

\section{Alimentos frescos minimamente processados embalados em atmosfera modificada}

Review:

\author{
Fresh, minimally processed foods packaged under modified atmosphere
}

\section{Autores | Authors}

৫ Joana Silva SANTOS

REQUIMTE

Departamento de Ciências Químicas

Faculdade de Farmácia

Universidade do Porto

Rua de Jorge Viterbo Ferreira, 228 CEP: $4050-313$

Porto - Portugal

e-mail: joanasantoscma@sapo.pt

Maria Beatriz Prior Pinto

OLIVEIRA

REQUIMTE

Departamento de Ciências Químicas

Faculdade de Farmácia

Universidade do Porto

Porto - Portugal

e-mail: beatoliv@ff.up.pt

Autor Correspondente / Corresponding Author

Recebido / Received: 30/08/2010 Aprovado | Approved: 05/12/2011 Publicado / Published: mar./2012

\section{Resumo}

Os alimentos frescos, minimamente processados e embalados sob atmosfera modificada atraem os consumidores que procuram produtos frescos e saudáveis, e que, ao mesmo tempo, são fáceis de transportar e preparar. A atmosfera no interior das embalagens consiste numa mistura de gases que está otimizada para cada alimento, de modo a preservar as suas qualidades durante mais tempo. A manutenção da temperatura de refrigeração durante 0 processamento, o armazenamento, a distribuição e a comercialização é essencial, por causa da natureza perecível dos produtos frescos minimamente processados. Este trabalho discute o estado de arte dos alimentos frescos minimamente processados (frutas, vegetais, carnes e pescados) embalados em atmosfera modificada, com uma descrição pormenorizada dos últimos desenvolvimentos nesse campo.

Palavras-chave: Embalagem em atmosfera modificada; Alimentos minimamente processados; Refrigeração.

\section{Summary}

Fresh, minimally processed foods packaged under modified atmospheres are attractive to consumers searching for fresh healthy products that are also easy to transport and prepare. The atmosphere inside the package is a blend of gases optimized for each type of food, such that the quality characteristics are preserved for longer. However, due to the perishable nature of minimally processed fresh foods, maintenance at refrigeration temperatures is essential during processing, storage, distribution and commercialization. This paper discusses the state of art of minimally processed fresh foods (fruit and vegetables, meat and fish) packaged under modified atmosphere, with a detailed description of the latest developments in this field.

Key words: Modified atmosphere package; Minimally processed food; Refrigeration. 


\section{Introdução}

O ritmo de vida atual faz com que os consumidores tenham cada vez menos tempo para se dedicar à alimentação, preferindo alimentos que sejam saudáveis e, simultaneamente, de preparação fácil e rápida (BUCKLEY et al., 2007; RAGAERT et al., 2004; KORHONEN, 2002). Além dessas características, os consumidores exigem outros atributos, nomeadamente uma elevada qualidade sensorial e segurança, preferencialmente, sem aditivos (MEYER et al., 2002).

Outras características desejadas são preparação rápida, refeições prontas para comer e facilidade de transporte, ou seja, produtos com reduzido tempo de preparação (BUCKLEY et al., 2007).

No entanto, não é coincidência que alguns dos alimentos nutricionalmente mais recomendados sejam também os que apresentam maiores desafios de conservação, uma vez que, para os consumidores mais conscientes, o problema não deverá ser resolvido com a adição de conservantes químicos.

Atualmente, está disponível uma grande variedade de alimentos preparados, refrigerados, com uma maior vida útil (período em que o alimento mantém a sua qualidade nutricional e microbiológica) (FELLOWS, 2000). Apesar de terem sofrido algum tipo de processamento, mantêm a qualidade do produto fresco, conseguida por meio da aplicação de novas técnicas de preservação moderadas, como a refrigeração, o aquecimento moderado, a embalagem em atmosfera modificada e o uso de sistemas antimicrobianos naturais. Nessa nova gama de produtos, os alimentos minimamente processados (MP), encontram-se os vegetais frescos cortados, a carne e o peixe fresco e filetado (ZEUTHEN, 2002). Esses alimentos são, habitualmente, comercializados já embalados para maior comodidade. Os alimentos MP surgiram para dar resposta a uma nova tendência de consumo e têm tido uma aceitação cada vez maior nos mercados mundiais.

Os alimentos MP não são produtos estéreis. Pelo contrário, apenas ocorre uma diminuiçao moderada da flora microbiana presente durante o processamento, exigindo-se um processo de refrigeração rigoroso, para evitar o crescimento de microrganismos patogênicos. Requerem, simultaneamente, condições de embalagem especiais, para garantir a sua segurança. Além da refrigeração e da embalagem, podem ainda usar-se outras barreiras ao crescimento dos microrganismos, que podem ser inerentes à matéria-prima ou introduzidas durante o processamento (ZEUTHEN, 2002).

A eficácia de muitas técnicas utilizadas na produção de alimentos MP depende fortemente da utilização de uma embalagem adequada para cada produto, adquirindo esta um papel importante em toda a cadeia de distribuição de alimentos, desde o agricultor até o consumidor. Além da manutenção da qualidade e de evitar uma contaminação posterior ao processamento, a embalagem pode ter ainda um papel fundamental na preservação do produto, como acontece nas embalagens ativas e com atmosfera modificada.

As técnicas para embalar alimentos evoluíram muito nas últimas décadas, respondendo à necessidade de manter o produto seguro, aumentar a sua vida útil, procurar uma melhor relação custo-benefício, responder a questões ambientais e também às exigências dos consumidores. Atualmente, o setor da embalagem representa uma indústria que gera bilhões de euros em todo o mundo, sendo $50 \%$ do mercado referente a embalagens de alimentos.

Uma das técnicas mais presentes no mercado europeu é a embalagem em atmosfera modificada (MAP), que consiste em substituir a atmosfera natural que rodeia o alimento por outra mistura de gases de composição conhecida, otimizada para cada tipo de produto. Esta retarda a degradação e preserva as características de qualidade durante mais tempo. Os gases mais utilizados são o dióxido de carbono $\left(\mathrm{CO}_{2}\right)$, o oxigênio $\left(\mathrm{O}_{2}\right)$ e o nitrogênio $\left(\mathrm{N}_{2}\right)$, misturados em diferentes proporções para se obter o melhor resultado (PHILIPS, 1996). No entanto, a MAP apenas é viável em mercados que possuam uma cadeia de frio bem implementada e controlada, e cujos consumidores possam suportar o preço de produtos de alto valor agregado (SIVERTSVIK et al., 2002a). A embalagem com atmosfera modificada pode ser aplicada a uma grande variedade de alimentos MP, desde vegetais frescos cortados a carnes, peixes, pães, produtos de confeitaria e lacticínios. Dependendo do tipo de produto, poderá obter-se uma extensão do período de vida útil de várias semanas. No entanto, por causa da natureza perecível dos produtos frescos MP, o controle e a manutenção da temperatura de refrigeração são essenciais durante todo o processamento, a distribuição, o armazenamento e a comercialização.

\section{Embalagem em Atmosfera Modificada (MAP)}

Nas últimas décadas, as técnicas de embalagem visam principalmente ao aumento da vida útil dos alimentos e baseiam-se, majoritariamente, na redução do teor de oxigênio que rodeia o produto. Exemplos: a embalagem a vácuo e a embalagem em atmosfera modificada.

Conforme o referido, a maioria dos alimentos MP necessita de refrigeração e de uma embalagem adequada, sendo esta essencial para controlar as interações entre o produto, o meio e o consumidor (HAUGAARD et al., 2001). 
Existem vários métodos e materiais para embalar alimentos MP, sendo uma área de grande crescimento e inovação no nível tecnológico. Essas inovações visam manter a qualidade dos alimentos durante um maior período de tempo, procurando, simultaneamente, produzir um menor impacto ambiental, por meio de novas aplicações de materiais obtidos de fontes renováveis (biopolímeros), compostáveis e/ou redução de material. No entanto, apesar das inovações, todas as embalagens continuam com quatro características comuns:

i) Conter o alimento;

ii) Proteger o produto, minimizando a perda de qualidade em todo o seu período de vida útil;

iii) Fornecer informação ao consumidor e funcionar como ferramenta de marketing;

iv) Facilitar a utilização, ou seja, oferecer conveniência aos consumidores (YAM et al., 2005).

Os materiais mais utilizados nas embalagens são plásticos e, em menor número, metais, vidro e papel. São materiais econômicos, versáteis e flexíveis, apesar de alguns não poderem ser reciclados (HAUGAARD e MORTENSEN, 2003).

Existem vários fatores a considerar no momento da escolha de um determinado tipo de embalagem, sendo necessário ter em mente as características do alimento, a forma de processamento, o tempo de vida útil pretendido e, acima de tudo, o custo de todo o processo de embalar o produto. Os avanços tecnológicos na área dos materiais e das técnicas utilizadas têm aumentado as opções de embalagem (LOPEZ-RUBIO et al., 2006). Uma das razões que levou à evolução dos materiais e das técnicas de embalagem dos alimentos foi a presença de uma maior cadeia de distribuição, acompanhada de uma maior preferência dos consumidores por alimentos frescos, seguros e com qualidade superior (CUTTER, 2006; YAM et al., 2005).
A embalagem em atmosfera modificada (MAP), também denominada de atmosfera protetora, está bastante presente no mercado de alimentos MP. Apesar de não ser uma técnica recente (SIVERTSVIK et al., 2002a; PHILIPS, 1996; SEIDEMAN e DURLAND, 1984), ganhou uma nova expressão desde que os alimentos MP começaram a suscitar um maior interesse nos consumidores (YUAN, 2003). Essa técnica possui vantagens e desvantagens que são enumeradas na Tabela 1.

A eficácia da MAP depende de vários fatores, nomeadamente, do tipo de alimento, da qualidade inicial da matéria-prima, da mistura de gases utilizada, da temperatura de armazenamento, das condições de higiene durante o processamento e das propriedades de barreira do material utilizado na embalagem (SIVERTSVIK et al., 2002a).

O princípio da aplicação da MAP é a substituição do ar existente no interior da embalagem $\left(78 \% \mathrm{~N}_{2}, 21 \% \mathrm{O}_{2}\right.$, $0,03 \% \mathrm{CO}_{2}$ ) por uma mistura de gases de concentração otimizada (FELLOWS, 2000; SEIDEMAN e DURLAND, 1984).

Os principais gases utilizados na MAP são o dióxido de carbono $\left(\mathrm{CO}_{2}\right)$, o oxigênio $\left(\mathrm{O}_{2}\right)$ e o nitrogênio $\left(\mathrm{N}_{2}\right)$. A razão entre volume de gases utilizado e produto deve ser de 2:1 ou 3:1, para evitar que ocorra o colapso da embalagem, em razão da grande solubilidade do $\mathrm{CO}_{2}$ nos alimentos com maior teor de umidade.

$\mathrm{O} \mathbf{C O}_{2}$ é considerado como o principal elemento das embalagens com atmosfera modificada, por seus efeitos bacteriostático e fungiostático. Consegue inibir o crescimento de muitas bactérias responsáveis pela degradação do produto, aumentando o efeito inibidor com a concentração. $\mathrm{O} \mathrm{CO}_{2}$ é muito solúvel em água $\left(179,7 \mathrm{~cm}^{3} / 100 \mathrm{~mL}\right.$ a $\left.0{ }^{\circ} \mathrm{C}\right)$ e gordura, e a sua solubilidade aumenta com a diminuição da temperatura, o que faz com que a eficácia desse método seja dependente do controle desse fator. Assim, a dissolução de $\mathrm{CO}_{2}$ nos alimentos vai depender do teor em água e gordura, e da pressão parcial do gás na atmosfera (Lei de Henry). Mesmo depois de aberta a embalagem, o $\mathrm{CO}_{2}$ mantém parte da sua ação conservante, por ser liberado de

Tabela 1. Vantagens e Desvantagens da utilização da MAP (adaptado de SIVERTSVIK et al., 2002a; PHILLIPS, 1996).

\begin{tabular}{ll}
\multicolumn{1}{c}{ Vantagens } & \multicolumn{1}{c}{ Desvantagens } \\
+ Aumento do período de vida útil (50-400\%) & - Aumento dos custos \\
+ Redução das perdas por expiração do prazo de validade & - Controle imprescindível da temperatura \\
+ Produto de melhor qualidade & - Especificação de atmosfera adequada a cada tipo de produto \\
+ Melhor separação de produtos fatiados & - Especificação de pessoal e equipamento especial \\
+ Com poucos ou mesmo sem adição de conservantes & - Maior volume das embalagens \\
+ Melhor apresentação dos produtos & - Perda de benefícios após abertura da embalagem \\
+ Embalagens seladas, barreiras contra a contaminação e & - A dissolução do $\mathrm{CO}_{2}$ pode levar ao colapso da embalagem \\
perda de líquidos & \\
\hline
\end{tabular}


forma lenta do produto (efeito residual). Ao dissolver-se em água, $\mathrm{O} \mathrm{CO}_{2}$ dá origem a ácido carbônico, que provoca um efeito acidificante. A solubilidade do $\mathrm{CO}_{2}$ interfere, também, na capacidade de retenção de água do alimento, provocando uma maior liberação de exsudados (SIVERTSVIK et al., 2002a).O mecanismo de ação do $\mathrm{CO}_{2}$ sobre os microrganismos é complexo, sendo resultado de uma combinação de vários eventos: alteração da função da membrana celular, interferindo com o transporte de íons; inibição direta de algumas enzimas ou apenas diminuição da atividade enzimática; alteração do pH no interior da células ao atravessar as membranas dos microrganismos, reagindo com a água no citoplasma, e alteração das propriedades fisicoquímicas das proteínas no interior dos microrganismos. Esses quatro eventos ocorrem com diferentes intensidades em todas as espécies de bactérias. No entanto, a taxa de crescimento e a fase de latência apresentam uma boa correlação com a utilização do $\mathrm{CO}_{2}$, sendo as bactérias Gram-negativas mais sensíveis do que as Gram-positivas (BRANDENBURG e ZAGORY, 2009; YUAN, 2003; SIVERTSVIK et al., 2002b).

$\mathrm{O} \mathbf{N}_{2}$ é um gás inerte e sem sabor, utilizado na MAP para preencher o espaço livre da embalagem, por causa da sua baixa solubilidade quer em água e gordura. Este não é absorvido pelo produto, prevenindo assim o colapso da embalagem devido à dissolução do $\mathrm{CO}_{2}$. $\mathrm{O}$ $\mathrm{N}_{2}$ é também utilizado para remover $\mathrm{O}_{2}$ em embalagens de produtos sensíveis à oxidação, como alternativa à embalagem a vácuo (SIVERTSVIK et al., 2002a).

$\mathrm{O}_{2}$ é um gás reativo que está presente como constituinte da maioria das moléculas orgânicas. É ligeiramente solúvel em água $\left(4,89 \mathrm{~cm}^{3} / 100 \mathrm{~mL}\right.$ a $\left.0{ }^{\circ} \mathrm{C}\right)$ e a sua solubilidade aumenta com a diminuição da temperatura. A maioria das reações com participação do $\mathrm{O}_{2}$ é de degradação (por exemplo, a oxidação), o que faz com que normalmente se evite a sua utilização. Contudo, este é necessário para a respiração de frutos e vegetais, para manter a cor nas carnes vermelhas e, também, para reduzir a perda de líquidos nas embalagens de peixes magros (BRANDENBURG e ZAGORY, 2009). Inicialmente, pensava-se que a sua presença poderia inibir o desenvolvimento de bactérias patogênicas anaeróbias. Contudo, segundo um estudo da ACMSF (Advisory Committee on the Microbial Safety of Food) de 1992, esse efeito não é linear (SIVERTSVIK et al., 2002a). Um exemplo desse fato verificou-se com o desenvolvimento do patogênio Clostridium botulinum, cuja presença parece, em alguns casos, ser independente da total exclusão ou inclusão de $\mathrm{O}_{2}$ nas embalagens (SKINNER e REDDY, 2006). É necessário perceber o impacto da modificação da atmosfera na flora microbiana presente e conhecer as técnicas de processamento mínimo que resultam numa maior inativação dos microrganismos, mantendo os atributos de qualidade do produto fresco desejados pelos consumidores.

Para a maior parte dos alimentos MP, são utilizadas misturas de dois ou três gases, escolhidas de acordo com o produto. Em produtos que não respiram (carnes, peixes, alimentos cozidos, produtos de panificação e alimentos secos) e nos quais o principal fator de degradação é a atividade microbiana, é utilizada uma mistura com cerca de $30-60 \%$ de $\mathrm{CO}_{2}$. Nos produtos que têm respiração (frutos e vegetais), a concentração de $\mathrm{O}_{2}$ não deve ser inferior a 5\%, sendo a mistura composta majoritariamente por $\mathrm{N}_{2}$. Nos produtos muito susceptíveis à rancidez, a mistura gasosa não deve conter $\mathrm{O}_{2}$ (SIVERTSVIK et al., 2002a).

Também podem ser utilizados o argônio e outros gases nobres (em frutos e vegetais), que têm uma função similar ao $\mathrm{N}_{2}$. Existem ainda outros gases que são aplicados de uma forma restrita, em razão da legislação, ou apenas aplicados em nível experimental. São estes: o monóxido de carbono (carnes vermelhas) (SEYFERT et al., 2007; EUROPEAN COMMISSION, 2001), o ozônio, o óxido de etileno, o óxido nitroso, o óxido de propileno, o vapor de etanol (produtos de panificação), o hidrogênio e o cloro (SIVERTSVIK et al., 2002a).

Um dos requisitos do material da embalagem a se utilizar com atmosfera modificada é a capacidade de reter a atmosfera, durante o maior período de tempo possível. A permeabilidade do filme aos gases e ao vapor de água, e a capacidade de manter a integridade da selagem da embalagem são essenciais para prolongar a vida útil do produto (MANGARAJ et al., 2009). A maioria dos materiais aplicados são constituídos por várias camadas, para garantir uma baixa permeabilidade ao vapor de água, uma elevada barreira aos gases e uma resistência mecânica ao manuseio (PAUL e CLARKE, 2002).

Os materiais mais utilizados podem ser simples, extrusados ou laminados de copolímeros de etilenoálcool vinílico $(E V O H)$, poliéster e polietileno, nylon e polietileno (PE), policloreto de vinila (PVC), polipropileno (PP), politereftalato de etileno (PET). O seu custo está diretamente relacionado com a sua maior ou menor capacidade de barreira aos gases. A transparência desses materiais é também um fator considerado na escolha, pois alguns produtos podem ser mais sensíveis à luz, podendo optar-se por materiais metalizados ou com aditivos anti-UV (MANGARAJ et al., 2009; SIVERTSVIK et al., 2002a; FELLOWS, 2000).

Há duas formas de se modificar a atmosfera que rodeia um alimento MP: a MAP passiva e a MAP ativa. $\mathrm{Na}$ primeira, o produto é embalado com ar normal $\left(78 \% \mathrm{~N}_{2}\right.$, $21 \% \mathrm{O}_{2}, 0,03 \% \mathrm{CO}_{2}$ ), sendo a embalagem selada com um filme permeável. A atmosfera no interior da embalagem vai alterar-se devido à respiração do produto (consumo de $\mathrm{O}_{2}$ e produção de $\mathrm{CO}_{2}$ ). A permeabilidade do filme 
vai permitir que se estabeleça um equilíbrio entre os ambientes externo e interno, conseguindo, desse modo, manter a qualidade do produto durante mais alguns dias. É difícil otimizar o processo por causa das diferentes taxas de respiração dos produtos e das diferentes taxas de permeabilidade dos filmes disponíveis no mercado.

No caso da MAP ativa, é injetada dentro da embalagem, antes da selagem, uma mistura de gases de concentração conhecida. A mistura é escolhida de acordo com o produto e com o filme da embalagem, de modo a controlar a taxa de respiração dos produtos, manter as características de qualidade e retardar o desenvolvimento dos microrganismos responsáveis pela degradação (YUAN, 2003; KADER e WATKINS, 2000).

Os alimentos MP embalados em atmosfera modificada apresentam alguma restrições em relação à sua segurança. Ao aumentar a vida útil, pode permitir-se o desenvolvimento de microrganismos patogénicos, que não seriam capazes de se desenvolver num período de vida mais reduzido (PHILIPS, 1996). É, por isso, útil distinguir dois tipos de alimentos MP embalados em MAP. Um primeiro grupo inclui os alimentos que são ingeridos sem nenhum processamento posterior ao embalamento, como refeições prontas para comer, frutos, vegetais, peixe e carne defumados. Os alimentos pertencentes ao outro grupo são os que serão submetidos a um processamento térmico, que será suficiente para eliminar os microrganismos presentes, antes de serem ingeridos, como, por exemplo, peixe, carne e aves frescas. Logo, os problemas de segurança microbiológica são uma prioridade nos produtos do primeiro grupo, sendo obrigatório o controle restrito da temperatura ao longo de todo o percurso do alimento. Para garantir a segurança dos produtos embalados em MAP, quando não se pode controlar toda a cadeia de frio, é aconselhável a utilização da Tecnologia de Barreiras. Esta consiste na conjugação de vários fatores, com uma intensidade subletal, que os microrganismos têm de ultrapassar para conseguirem desenvolver-se. A aplicação dessa técnica implica um conhecimento das interações de vários fatores, como a temperatura, a atividade da água $\left(a_{w}\right), o p H$ e a pressão, entre outros, para desenvolver um produto que seja seguro em nível microbiológico (YUAN, 2003). Os fatores combinados nessa técnica podem ser físicos, fisicoquímicos, microbiológicos ou mistos (LEISTNER e GORRIS, 1995), sendo os mais importantes a temperatura, a atividade da água $\left(\mathrm{a}_{\mathrm{w}}\right)$, a acidez, o potencial redox (Eh), a presença de microrganismos competitivos - como a presença de bactérias do ácido lático - e o uso de conservantes, como nitritos e sulfitos. No entanto, o uso de cada barreira está limitado pela probabilidade de gerar sabores estranhos. Por outro lado, a combinação de barreiras a aplicar terá de ser definida de acordo com o produto, porque é dependente da carga microbiana inicial do alimento e das condições favoráveis ao desenvolvimento de microrganismos que aí existem, e também da vida útil que é pretendida para esse produto.

As boas práticas de fabricação e higiene, e o controle restrito da temperatura em toda a cadeia de processamento e distribuição, bem como um plano de HACCP da cadeia de produção, são essenciais para garantir a segurança e a qualidade de um alimento MP embalado em atmosfera modificada (PHILIPS,1996; YUAN, 2003). É também preciso não esquecer que a MAP não melhora a qualidade inicial de um produto, mantendo, em condições ideais, a qualidade existente no momento da selagem da embalagem. Isso faz com que as condições de colheita, abate, manuseio e processamento sejam determinantes para a qualidade do produto final (BRANDENBURG e ZAGORY, 2009).

A tecnologia aplicada na MAP tem algumas limitações. Contudo, ao aplicar as técnicas de MAP em conjunto com outras técnicas de embalagem ativas ou "inteligentes", a eficácia e a segurança podem aumentar (SIVERTSVIK et al., 2002a). Trata-se de uma nova era de embalagens em atmosfera modificada, que deixam de depender exclusivamente da mistura de gases introduzida e das características do filme utilizado (YAM et al., 2005; HANSEN et al., 2008). Nesses sistemas, ocorre uma interação entre a embalagem, o produto e o ambiente para se atingir uma maior vida útil. A composição da atmosfera que rodeia o alimento é alterada ao longo do tempo, de modo a melhorar também a segurança do produto e/ou as suas características sensoriais. Um dos métodos mais comuns para criar uma embalagem ativa consiste na colocação, no interior da embalagem, de saches com capacidade de absorver - como o $\mathrm{O}_{2}$, $\mathrm{O}$

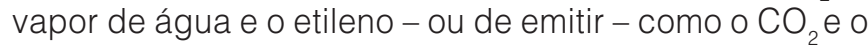
etanol - um determinado gás, para gerar uma atmosfera mais favorável no interior da embalagem. Podem também ser adicionados outros compostos ativos, como antimicrobianos, antioxidantes, enzimas e aromatizantes, que ajudam a prevenir a degradação do alimento e que podem melhorar a sua qualidade (YAM et al., 2005).

Apesar das vantagens da MAP, a adoção dessa técnica tem sido relativamente lenta em alguns países, que não possuem condições para a sua aplicação. Essa técnica ainda não atingiu todo o seu potencial, mas com os avanços tecnológicos mais recentes, no nível dos materiais e equipamentos, é de se prever uma maior disseminação da mesma (MANGARAJ et al., 2009).

\section{Frutas e hortaliças minimamente processados em MAP}

O consumo de frutas e hortaliças é essencial numa alimentaçao saudável. Essa ideia é reforçada pelas recomendações emitidas por várias organizações mundiais, como a WHO e a FAO, que aconselham o 
consumo de frutas e hortaliças para reduzir o risco de doenças cardiovasculares e para melhorar a condição física (ALLENDE et al., 2006). Com o aumento do número de opções de frutas e hortaliças minimamente processadas, surgiu uma opção rápida e prática para consumir esses alimentos. Como é sabido, estes devem manter-se saborosos, seguros e fáceis de preparar, apesar de poderem decorrer vários dias entre o momento do processamento e o consumo. O processamento desses produtos conduz invariavelmente a um processo de degradação fisiológica, bioquímica e microbiológica mais acelerado (RAGAERT et al., 2007; ALLENDE et al., 2006). Por esse motivo, a utilização da MAP em frutas e hortaliças MP deve levar em consideração a fisiologia do produto, uma vez que se embalam tecidos vivos que requerem de uma adequação da tecnologia aplicada, para que a sua utilização seja eficaz (BRANDENBURG e ZAGORY, 2009).

Para conseguir a manutenção das características do produto fresco, sem perda de qualidade nutricional e com o aumento do período de vida útil, é necessário perceber os mecanismos de degradação de cor, textura e sabor, para tentar retardá-los. Os principais mecanismos de degradação fisiológica e bioquímica advêm da ação de enzimas liberadas durante o processamento - descasque, corte, etc. -, sendo as mais importantes a polifenol oxidase, que provoca o escurecimento, e a lipoxidase, que catalisa reações de peroxidação, originando aldeídos e cetonas com cheiro desagradável. Ocorre também um aumento da produção de etileno, que acelera o processo de maturação, e um aumento da taxa de respiração entre 20 e $700 \%$, dependendo do produto e do tipo de processamento. As alterações devidas à atividade microbiana também aumentam, pois o processamento expõe ao ar o interior do produto, criando condições para contaminação por bactérias, leveduras e bolores. As espécies de microrganismos presentes nesses produtos podem variar muito, de acordo com o produto ou com o tipo de embalagem utilizada (RAGAERT et al., 2007; FRANCIS e O'BEIRNE, 2001). Ao utilizar a MAP, o desenvolvimento de microrganismos específicos da degradação pode ser suprimido, o que aumenta a vida útil, mas, por sua vez, pode criar a oportunidade para o desenvolvimento de patogênicos de crescimento mais lento (CHUA et al., 2008; ROSNES et al., 2003).

As espécies patogênicas psicotróficas podem desenvolver-se em temperaturas de refrigeração ou quando ocorre uma quebra da cadeia de frio, sendo a Listeria monocytogenes, a Aeromonas hydrophila e o Clostridium botulinum as mais comuns. Outras espécies que levantam muitas preocupações aos produtores de frutas e hortaliças MP por serem, também, responsáveis pelo aparecimento de doenças de origem alimentar são Escherichia coli O157:H7, Salmonella spp.,
Yersinia enterolitica, Campylobacter jejuni e alguns vírus e protozoários. A sua presença nos alimentos devese, essencialmente, a problemas de contaminação do solo e da água, bem como a inadequadas práticas de higiene (CHUA et al., 2008). Contudo, os vegetais MP são considerados alimentos seguros em relação a outros, pois a sua acidez natural atua como uma barreira ao desenvolvimento microbiano. Toda a etapa de processamento deve decorrer num ambiente limpo, aplicando-se as Boas Práticas de Fabricação e de Higiene, e o processo sendo controlado por meio de um plano de HACCP para prevenir os riscos microbiológicos e outros que possam surgir.

A temperatura em que são preparados e armazenados os vegetais MP é o fator mais importante para a preservação. Um armazenamento a $10{ }^{\circ} \mathrm{C}$ é perigoso, pois é o suficiente para que a maioria dos microrganismos patogênicos presentes se desenvolva nos produtos pré-cortados. Durante o processamento, o transporte, o armazenamento e a comercialização, a temperatura não deve exceder $8{ }^{\circ} \mathrm{C}$; devem-se também evitar flutuações desse fator, pois isso aumenta a velocidade de degradação, provocando também a formação de condensação no interior da embalagem, a qual é propícia ao desenvolvimento de microrganismos (AHVENAINEN, 2000).

Ao manter a concentração de $\mathrm{O}_{2}, \mathrm{CO}_{2}$ e etileno dentro dos valores ótimos para aquele produto, é possível aumentar a vida útil entre $50-100 \%$, relativamente ao seu armazenamento em ar (KADER, 2009). Normalmente, as misturas gasosas utilizadas possuem 2-5\% de $\mathrm{O}_{2}$ e $\mathrm{CO}_{2}$, sendo a restante da composição preenchida por $\mathrm{N}_{2}$. Um dos maiores problemas para o sucesso da atmosfera aplicada aos frutos e vegetais MP é determinar a composição mais adequada a cada tipo de produto. Vários estudos testaram a composição mais favorável a vários tipos de produtos, verificando se a utilização da MAP traz ou não vantagens para a conservação, ou seja, se a qualidade do alimento se mantém ao longo de um maior período de tempo (MARRERO e KADER, 2006; MARTÍNEZ-FERRER et al., 2002).

Ao reduzir-se a concentração de $\mathrm{O}_{2}$ que rodeia os vegetais, a sua taxa de respiração diminui, o que indiretamente retarda o seu processo de maturação e pode, em alguns casos, reduzir o processo de escurecimento por oxidação, reação problemática em vegetais folhosos. A utilização de uma baixa concentração de $\mathrm{O}_{2}$, juntamente com a refrigeração durante algum tempo, é importante para provocar a desinfestação dos produtos de larvas e insetos, um dos problemas que mais preocupam os produtores. No entanto, deve-se evitar que a concentração de $\mathrm{O}_{2}$ seja demasiado baixa, levando à formação de uma atmosfera de anaerobiose, a qual faz com que o metabolismo respiratório do produto 
produza acetaldeído e etanol, que causam odores e sabores estranhos. Também o desenvolvimento de microrganismos patogênicos anaeróbios é um dos grandes problemas da atmosfera anaeróbica em torno dos vegetais MP (BRANDENBURG e ZAGORY, 2009).

A utilização de uma concentração de $\mathrm{CO}_{2}$ superior à concentração atmosférica produz uma ligeira inibição na respiração de frutas e hortaliças frescas, o que contribui para o aumento da vida útil. A presença do $\mathrm{CO}_{2}$ diminui a sensibilidade da planta ao etileno; contudo, uma concentração desse gás superior à gama ótima de cada produto pode diminuir a qualidade, em razão de um processo de maturação desequilibrado, do qual surgem manchas e sabores e odores estranhos (BRANDENBURG e ZAGORY, 2009).

Outros gases testados na composição da atmosfera que mais se mostra adequada aos vegetais frescos embalados foram o monóxido de carbono (CO) e o dióxido de enxofre $\left(\mathrm{SO}_{2}\right)$. O CO é um gás extremamente tóxico, que apresenta um grande efeito inibidor sobre o desenvolvimento de microrganismos. No entanto, em função de sua natureza tóxica e explosiva (12,5 - 74,2 kPa em ar), o seu uso é bastante reduzido e desaconselhado em produtos MP. $\mathrm{O} \mathrm{SO}_{2}$ tem sido utilizado para controlar o desenvolvimento de fungos e bactérias em frutos como a uva e em frutos secos. Também apresentou resultados positivos quando aplicado em sucos de fruta, vinho, camarão, pickles e embutidos. No entanto, a presença de sulfitos nos alimentos pode desencadear reações de hipersensibilidade numa parte da população, o que faz com que a utilização desse gás tenha sido alvo de vários regulamentos, sendo a sua utilização limitada a determinados alimentos (BRANDENBURG e ZAGORY, 2009).

Os filmes a serem utilizados na embalagem de vegetais minimamente processados devem ter permeabilidade adequada a taxas de respiração muito elevadas. Os filmes com microperfurações, que permitem trocas de gases de modo controlado, são os mais utilizados para evitar que se desenvolva um ambiente anaeróbio propício ao desenvolvimento de espécies patogênicas. Com as microperfurações, a taxa de permeabilidade do filme está dependente da configuração, geometria e tamanho dos orifícios, que possuem entre 40 e 200 um de diâmetro (BRANDENBURG e ZAGORY, 2009). A escolha do filme certo torna-se mais complicada quando se pretende embalar uma salada de vegetais, que contém produtos com diferentes taxas de respiração. A solução adotada pela maioria dos produtores passou pelo estudo das taxas de respiração de cada produto, individualmente, tentando depois agrupar os que possuem um comportamento semelhante (BRANDENBURG e ZAGORY, 2009).
O valor nutricional desses alimentos frescos é uma das razões que levam os consumidores a escolhê-los, especialmente como fonte de vitaminas ( $C, A, B 6$, tiamina e niacina), minerais, fibras e outros constituintes, como flavonoides, carotenoides, polifenóis, entre outros fitoquímicos, que podem desempenhar um papel na diminuição do risco de câncer e outras doenças. No entanto, o impacto que o processamento mínimo e o maior período de vida útil têm sobre a qualidade nutricional ainda não está bem estabelecido (ALLENDE et al., 2006). Um estudo realizado por Lee e Kader (2000) mostrou que a quantidade de ácido ascórbico diminui em alguns vegetais minimamente processados. Este é também afetado pelo dano físico provocado pelo processamento e pelo frio, por longos períodos de armazenamento, por temperaturas elevadas e por teor de umidade baixo (KADER, 2009). Sabe-se, também, que nem todas as cultivares respondem da mesma forma ao processamento mínimo, existindo umas mais adequadas do que outras (KADER, 2009; FRANCIS e O'BEIRNE, 2001; AHVENAINEN, 2000). Em um estudo de Tudela et al. (2002), foi avaliado o teor de vitamina C de várias cultivares de batatas MP, ao longo do tempo, em três situações diferentes: embalagem com ar normal, MAP passiva e ultracongelamento. Os teores de vitamina $C$ nas batatas embaladas em atmosfera modificada diminuíram, possivelmente em função da elevada percentagem de $\mathrm{CO}_{2}$ que se acumulou no interior da embalagem por causa da inadequada permeabilidade do filme utilizado. Já um estudo realizado por Granado-Lorencio et al. (2008) mostrou que a MAP de brócolis MP não alterava significativamente a biodisponibilidade in vivo dos carotenóides e dos tocoferóis dos brócolis em humanos, concluindo que esse tipo de embalagem é adequado para manter a qualidade nutricional do produto.

\section{Carne minimamente processada em MAP}

A carne é um dos alimentos mais presentes na alimentação humana, apresentando uma tendência para o aumento do consumo em razão do crescimento da população mundial. A carne de bovina, suína e de aves é uma das principais fontes de proteínas na alimentação humana (OECD-FAO, 2008).

O corte e a forma de embalar carne fresca refrigerada em pequenos estabelecimentos comerciais têm sido substituídos pela oferta de embalagens individuais pré-preparadas, principalmente nos países desenvolvidos. Estima-se que esta é a forma de venda de $43 \%$ da carne fresca na Europa e de 64\%, nos Estados Unidos. A centralização do processo de embalar a carne num único local, que depois distribui pelos diferentes locais de venda, acarreta vantagens para produtores e comerciantes. Verifica-se um maior aproveitamento de espaço e da mão de obra necessária, uma melhoria da 
qualidade e a redução de resíduos produzidos. Permite também uma maior facilidade de automatização dos processos, uniformidade dos cortes, melhor controle de estoques, minimizando os custos do processo (MCMILLIN, 2008).

No momento da compra, o consumidor escolhe de acordo com alguns critérios, como o preço, a segurança, o valor nutricional, a qualidade sensorial e também a facilidade de transporte e de preparação. Com a mudança de hábitos de compra desses produtos, foi necessário desenvolver técnicas de embalagem que permitissem ao consumidor escolher com maior facilidade e segurança. A embalagem de carne em atmosfera modificada tornou-se uma opção para os produtores, uma vez que havia procura pelos consumidores e disponibilidade de tecnologia, de novos materiais de embalagem e dos equipamentos, permitindo aumentar a eficiência do processamento (MCMILLIN, 2008).

As propriedades da carne que determinam a sua vida útil são a cor, a capacidade de retenção de água, a qualidade microbiológica, a estabilidade lipídica e o sabor. Quando está embalada em MAP, a vida útil vai depender também da mistura gasosa, do material da embalagem, da razão volume gás/produto, da temperatura de armazenamento e da presença de aditivos (MCMILLIN, 2008). O músculo dos animais é, normalmente, estéril, sendo contaminado ao longo da cadeia de processamento, embalagem e distribuição. A contaminação pode ter origem no próprio animal, no momento de abate, em que o músculo pode ter contato com tecidos do trato respiratório e gastrointestinal, e nódulos linfáticos, que possuem uma flora microbiana específica e que podem sofrer dano durante o processo. O método utilizado para o abate e o corte da carne, bem como o equipamento utilizado, podem também ser vias de contaminação. Os funcionários que executam o processamento podem também provocar a contaminação do alimento (PAULSEN e SMULDERS, 2003).

A deterioração da aparência e do odor levam à rejeição do produto pelo consumidor. A cor, principalmente nas carnes vermelhas é um parâmetro associado à qualidade e ao frescor (ANTONIEWSKI et al., 2007; SEIDEMAN e DURLAND, 1984). Quando a superfície da carne é exposta ao ar, o oxigênio liga-se de modo reversível à mioglobina das fibras musculares (cor púrpura da mioglobina reduzida), formando oximioglobina, que confere à carne uma cor vermelho vivo, que identifica o produto como fresco. No entanto, uma exposição prolongada ao oxigénio leva à oxidação da oximioglobina à metamioglobina, que confere ao produto uma cor acastanhada, não apreciada pelos consumidores (MANCINI et al., 2009; CHOULIARA et al., 2008; CUTTER, 2006). A oxidação da mioglobina e o desenvolvimento de microrganismos são as principais causas de degradação da aparência da carne fresca, a qual tem uma grande influência na escolha do consumidor.

A concentração de $\mathrm{O}_{2}$ na mistura é essencial para manter a coloração vermelha da carne (por exemplo, a carne bovina), sendo utilizado numa concentração elevada (70-80\%) para favorecer a formação de oximioglobina. Com uma pressão parcial de $\mathrm{O}_{2}$, há uma maior formação de mioglobina reduzida e metamioglobina, que conferem à carne uma cor acastanhada, que o consumidor associa a um estado de degradação avançado. Para evitar a deterioração provocada pela presença de bactérias aeróbias, normalmente do gênero Pseudomonas, é necessária a presença de $\mathrm{CO}_{2}$ na mistura (20-30\%), sendo recomendado que a razão entre volume de gás/produto seja de 2:1, para que a embalagem não colapse durante a vida útil do produto (EILERT, 2005; SIVERTSVIK et al., 2002a).

Uma alternativa ao uso de elevadas percentagens de $\mathrm{O}_{2}$ nas embalagens de carnes vermelhas é aplicada na Noruega desde 1985 e consiste na utilização de uma mistura com uma concentração elevada de $\mathrm{CO}_{2}(60-70 \%)$, 30 a $40 \%$ de $\mathrm{N}_{2}$ e uma concentração inferior a 0,5\% de monóxido de carbono (CO). A presença deste gás na mistura promove a formação de carboximioglobina. Esta é mais resistente à oxidação que a oximioglobina e a metamioglobina, por causa da ligação forte entre o monóxido de carbono (CO) e o Ferro (Fe) do grupo heme da molécula de mioglobina (EUROPEAN COMMISSION, 2001). Garante-se, assim, uma estabilização da cor vermelha da carne, permitindo aumentar o tempo de vida útil do alimento. Há, no entanto, o aspecto controverso de a cor se manter aceitável além do período de segurança microbiológica, podendo mascarar a deterioração e permitir o desenvolvimento de microrganismos patogênicos. Contudo, após um estudo realizado por uma comissão científica da União Europeia, esta concluiu que a utilização do CO nas MAP's de carnes vermelhas não apresenta riscos para a saúde humana, recomendando a manutenção das condições de refrigeração estáveis. Os estudos analisados mostraram, igualmente, que o $\mathrm{CO}$ também tem um efeito inibidor no desenvolvimento de alguns patogênicos, entre os quais a $Y$. enterolitica, a L. monocytogenes, a E. coli O157:H7 e a Salmonella spp. Também a FDA, em 2004, analisou a utilização de CO na composição da atmosfera protetora de carnes vermelhas, concluindo que o seu uso em quantidades pequenas não impedia a degradação do produto. Apesar de haver uma conservação da cor, outros indicadores de degradação, como o desenvolvimento de maus odores e sabores, não são inibidos (EILERT, 2005).

No caso da carne suína, é recomendada a utilização de uma mistura de gases sem $\mathrm{O}_{2}$ por causa do efeito negativo deste sobre os lípidios da carne (ranço) (SIVERTSVIK et al., 2002a). Essa situação é 
também comum às carnes brancas - por exemplo, a carne de aves -, nas quais a estabilização da cor não é um parâmetro essencial, sendo a degradação microbiana e a oxidação lipídica os principais problemas a considerar. Nesses produtos, a mistura de gases mais eficiente é constituída por uma elevada concentração de $\mathrm{CO}_{2}$ (superior a $20 \%$ ), sendo a restante percentagem de $\mathrm{N}_{2}$ (SIVERTSVIK et al., 2002a). Estudos realizados por Chouliara et al. (2008), Rajamäki et al. (2006) e Rokka et al. (2004) mostraram que numa MAP de carne de frango, a percentagem de $\mathrm{CO}_{2}$ pode atingir $70-80 \%$, sem ocorrer perda de qualidade sensorial.

O controle da temperatura de armazenamento da carne MP é essencial para prevenir o desenvolvimento de microrganismos e estabilizar a cor. A temperaturas superiores a $3^{\circ} \mathrm{C}$, a mioglobina reduzida é mais facilmente oxidada à metamioglobina. As Pseudomonas são os microrganismos aeróbios mais comuns nesses produtos e, na presença de $\mathrm{O}_{2}$, utilizam a glucose disponível no alimento para o seu metabolismo, sem provocar deterioração sensorial do produto. Quando já não existe glucose, estas começam a degradar os aminoácidos livres, gerando vários produtos que conferem um cheiro pútrido ao produto (aminas biogênicas). Quando a carne é colocada num ambiente com elevada concentração de $\mathrm{CO}_{2}$, o desenvolvimento das Pseudomonas é inibido, permitindo o desenvolvimento das bactérias produtoras de ácido lático, como o Lactobacillus spp., cuja ação degradativa não é tão intensa (WALSH e KERRY, 2002). Também com a carne MP, a utilização de uma combinação de várias barreiras ao desenvolvimento microbiano pode contribuir para uma melhor preservação, tendo já atingido bons resultados a aplicação de revestimentos comestíveis (ANTONIEWSKI et al., 2007) e alguns agentes bioativos antimicrobianos, de embalagens ativas e inteligentes, ou mesmo por meio de uma técnica de processamento mínimo com irradiação (VAIKOUSI et al., 2009; AYMERICH et al., 2008; CHOULIARA et al., 2008).

\section{Pescado minimamente processado em MAP}

O pescado é reconhecido, pelos consumidores, como um alimento saudável e nutricionalmente completo. Essa percepção é também apoiada pela inclusão do pescado na lista dos alimentos "funcionais", o que se deve essencialmente ao seu elevado teor em ácidos graxos insaturados da série $\mathrm{n}-3$. O consumo de peixe, duas vezes por semana, é recomendado pelo Comitê Internacional de Orientações Dietéticas para prevenir doenças cardiovasculares, câncer do cólon e doenças inflamatórias do intestino. No entanto, para que possa exercer todos os potenciais benefícios, sem qualquer risco para a saúde humana, é necessário que esse produto se mantenha seguro, sem contaminantes e com qualidade até o momento em que chega ao consumidor (POLI, 2005).

O pescado é um alimento muito perecível, que possui uma flora microbiana bastante complexa em função da contaminação específica e não específica do animal no ambiente de origem, da contaminação durante o processamento e ainda da contaminação em razão de fatores intrínsecos e extrínsecos, que determinam o seu desenvolvimento, como temperatura, pH e interações entre várias espécies de microrganismos. A sua degradação é, majoritariamente, provocada pelo desenvolvimento microbiano. O pescado é, normalmente, comercializado em gelo ou a temperaturas de refrigeração, sem mais nenhuma embalagem. Nessas condições, pode apresentar uma vida útil de 5 a 10 dias, dependendo da espécie, do local de origem e da estação do ano. Por essa elevada perecibilidade, o pescado, em grande parte, não é comercializado fresco, mas sim congelado ou preservado por meio de outras técnicas, como as conservas, a salga ou a defumação (REDDY et al., 1999). Para aumentar a oferta de pescado fresco no mercado, foi necessário recorrer a novas técnicas de preservação, que permitissem aumentar a vida útil desse produto, para que pudesse suportar uma cadeia de distribuição mais longa, típica dos mercados atuais.

Apesar de ser um alimento saudável, os consumidores não reconhecem o pescado como um produto conveniente, ou seja, a compra e a preparação deste não se encaixam nas preferências dos novos consumidores, que não querem dispender muito tempo na preparação das suas refeições. Ao disponibilizar o pescado já limpo e filetado numa embalagem com atmosfera modificada, o produto torna-se mais atrativo.

A utilização de MAP pode significar um aumento da vida útil do pescado de 50 a $100 \%$ nos peixes crus e de 100 a 200\% no marisco cozido (SIVERTSVIK, et al., 2002b; HOVDA et al., 2007). Existem inúmeros estudos que investigaram a composição das misturas de gases e a temperatura de armazenamento mais adequada a diferentes espécies de pescado. No entanto, por não ser referida a razão volume de gás/produto utilizado, a variação da concentração dos gases ao longo do tempo, entre outros aspectos, faz com que seja difícil comparar os resultados (SIVERTSVIK, et al., 2002b). Huss (1995) refere que o aumento de vida útil de pescado filetado em MAP pode ser de alguns dias até uma semana ou mais, quando comparado com o armazenamento com ar normal, dependendo esse valor da espécie e da temperatura de conservação.

A degradação microbiana é responsável pela rápida perda de qualidade do pescado exposto ao ar. Por isso, as misturas gasosas utilizadas nesses produtos possuem uma elevada concentração de $\mathrm{CO}_{2}$ para inibir 0 desenvolvimento bacteriano. A função do $\mathrm{O}_{2}$ nas 
misturas é inibir a redução do óxido de trimetilamina a trimetilamina no peixe fresco (SIVERTSVIK, et al., 2002b). Uma mistura com 40-60\% de $\mathrm{CO}_{2}$ e $40-60 \%$ de $\mathrm{N}_{2}$, sem nenhum $\mathrm{O}_{2}$, é aconselhada na atmosfera de embalagens de peixes gordos, como salmão, truta, sardinha, arenque etc., uma vez que a oxidação lipídica das gorduras insaturadas, presentes nessas espécies, resulta na produção de odores intensos. A embalagem a vácuo é, também, uma alternativa menos dispendiosa nesses casos. No entanto, a inibição microbiana atinge melhores resultados quando é utilizada a MAP (ÖZOGUL et al., 2004; SIVERTSVIK, et al., 2002a; REDDY et al., 1999). Para os peixes magros, como bacalhau, pescada e dourada, os crustáceos e os moluscos, a atmosfera deve conter $40 \%$ de $\mathrm{CO}_{2}$ e $60 \%$ de $\mathrm{N}_{2}$ ou $40 \%$ de $\mathrm{CO}_{2}, 30 \%$ de $\mathrm{O}_{2}$ e $30 \%$ de $\mathrm{N}_{2}$. O $\mathrm{O}_{2}$, além do efeito já referido, reduz a formação de exsudados. A concentração de $\mathrm{CO}_{2}$ e a razão volume de gás/produto são determinantes para aumentar a vida útil dos alimentos; a razão recomendada para os peixes frescos é uma proporção de 2:1 ou 3:1 (GOULAS e KONTOMINAS, 2007; HOVDA et al., 2007; SIVERTSVIK, et al., 2002a)

Nos peixes marinhos apenas armazenados em gelo, as bactérias predominantes são a Shewanella putrefaciens e a Pseudomonas, independentemente do local de captura. Entretanto, se o pescado for colocado a uma temperatura de $25^{\circ} \mathrm{C}$, a microflora será dominada pelas bactérias mesófilas, como as Vibrionaceae e as Enterobacteriaceae, no caso de ter sido capturado num local poluído. As Aeromonas são as principais responsáveis pela degradação microbiana nos peixes de água doce. Na presença de $\mathrm{CO}_{2}$, o desenvolvimento de Shewanella putrefaciens e de Pseudomonas é inibido, sendo o Photobacterium phosphoreum o principal responsável pela degradação de filé de bacalhau numa atmosfera rica em $\mathrm{CO}_{2}$, em ambiente refrigerado. $O$ P. phosphoreum existe no meio marinho e revelou um desenvolvimento elevado em condições de anaerobiose e uma elevada resistência ao $\mathrm{CO}_{2}$, sendo, por isso, o organismo responsável pela degradação da maioria do pescado MP embalado em atmosfera modificada (HANSEN et al., 2007; ÓLAFSDÓTTIR et al., 1997; DALGAARD et al., 1993). A bactéria Brochotrix thermosphacta foi a espécie responsável pela degradação na fase final de armazenamento da maioria das amostras em MAP, refrigeradas $\left(4{ }^{\circ} \mathrm{C}\right)$ de alabote (Hippoglossus hippoglossus), analisadas por Hovda et al. (2007).

Também para o pescado MP em MAP, a temperatura é o fator mais importante durante todo o processamento, a distribuição e o armazenamento, porque influi largamente tanto na atividade enzimática como na microbiana (REGENSTEIN, 2006). O nível de segurança dos produtos também é maior quando estes são refrigerados a
$4{ }^{\circ} \mathrm{C}$. Em um estudo realizado com quatro espécies de peixes (bacalhau, tilápia, peixe-gato e salmão) sobre o desenvolvimento da toxina do Clostridium botulinum em embalagens expostas ao ar, a vácuo e em MAP $\left(75 \% \mathrm{CO}_{2}\right.$ e $\left.25 \% \mathrm{~N}_{2}\right)$ a 4,8 e $16{ }^{\circ} \mathrm{C}$, foi demonstrado que, após o final da vida útil nos produtos embalados em MAP e armazenados a $4{ }^{\circ} \mathrm{C}$, não se desenvolveu tal toxina (REDDY et al., 1999). Normalmente, a degradação sensorial antecede a formação de toxinas. No entanto, essa margem de segurança, além de variar com a temperatura, também foi diferente nas espécies testadas, sendo o bacalhau o que apresentou um maior intervalo de dias, armazenado a $8{ }^{\circ} \mathrm{C}$ (REDDY et al., 1999). Por outro lado, em alguns estudos sobre o desenvolvimento de toxina botulínica em amostras de peixe em MAP, inoculadas com esporos de Clostridium botulinum tipo E e armazenadas a $8{ }^{\circ} \mathrm{C}$, ocorreu a formação da toxina antes da rejeição sensorial do produto. Essa informação levanta algumas questões em relação à utilização da MAP; no entanto, existem ainda questões que não se encontram explicadas, como é o caso da interação dessa bactéria com outros fatores, como a permeabilidade do filme utilizado e os gases que compõem a atmosfera (WANG et al., 2008).

A temperatura de refrigeração utilizada com a MAP pode atingir melhores resultados se for cerca de 1 a $2{ }^{\circ} \mathrm{C}$ abaixo do ponto de congelação do alimento. Esse método é denominado de "super refrigeração" e provoca a formação de alguns cristais de gelo. $O$ efeito sinérgico da MAP e da "super refrigeração" consegue prolongar mais a vida útil do produto, em razão de uma maior dissolução do $\mathrm{CO}_{2}$. Em um estudo apresentado por Sivertsvik et al. (2003), obteve-se um aumento de 2,5 vezes na vida útil de filé de salmão, em relação ao armazenamento com a mesma atmosfera a $4{ }^{\circ} \mathrm{C}$. Em um estudo em lombos de bacalhau em MAP, a aplicação da "super refrigeração" aumentou em 7 dias a vida útil do produto (WANG et al., 2008).

O pescado MP pode ter na sua microflora organismos patogênicos, os quais o processamento mínimo e a MAP não eliminam, podendo mesmo, em certos casos, como, por exemplo, o abuso de temperatura da cadeia de distribuição, potencializar o seu desenvolvimento. A segurança desses alimentos é, por isso, uma grande preocupação para os produtores, uma vez que existe a possibilidade de os seus produtos serem veículo para a transmissão de doenças de origem alimentar. No pescado embalado em MAP é, também, possível distinguir duas categorias de produtos: os que vão ser consumidos sem nenhum tratamento térmico, como, por exemplo, sashimi, sushi, salmão defumado e marisco cozido, e aqueles que serão cozidos, como o peixe fresco. Os microrganismos patogênicos que podem estar presentes nesses alimentos encontram-se 
naturalmente no meio aquático (C. botulinum tipo $\mathrm{E}, \mathrm{B}$ e F, Vibrio spp., A. hydrophila, Plesiomonas shigelloides), são frequentes nesse ambiente (Listeria monocytogenes, C. botulinum tipo A, B, C. perfringens, Bacillus spp.) ou têm uma origem animal/humana (Salmonella, Shigella, E. coli, Staphylococcus aureus). O risco de desenvolvimento da maioria dessas espécies de bactérias não aumenta com a utilização da MAP, sendo o seu crescimento inibido pela presença de uma atmosfera diferente do ar e pela baixa temperatura de armazenamento. É, também, aconselhável o uso de mais barreiras ao desenvolvimento microbiológico (Tecnologia de Barreiras) em conjunto com a MAP e a refrigeração, como a adição de sal e óleo de orégano (GOULAS e KONTOMINAS, 2007) e de ácido láurico (PASTORIZA et al., 2002), para conseguir aumentar o período de vida útil com maior segurança.

A aplicação de uma nova metodologia baseada na ação antimicrobiana do $\mathrm{CO}_{2}$, mais precisamente na ação preservativa da dissolução de $\mathrm{CO}_{2}$ no produto, conseguiu aumentar a vida útil de alimentos quando aplicada antes de se embalar, sob uma atmosfera modificada (ROTABAKK et al., 2006). Essa técnica denomina-se SGS (Soluble Gas Stabilisation) e é um procedimento realizado a pressões elevadas e a $0{ }^{\circ} \mathrm{C}$, resultando em um produto no qual existe uma saturação de $\mathrm{CO}_{2}$. Esse fato, além de aumentar a vida útil do produto, possibilita a utilização de uma embalagem de menor volume, pois permite reduzir a razão volume de gás/produto. A aplicação dessa técnica foi já testada com resultados positivos em filé de dourada e robalo (MENDES e GONÇALVES, 2008). Schirmer et al. (2009) apresentaram também uma nova técnica de embalagem com MAP, que combina as vantagens da presença da atmosfera com aquelas de uma embalagem a vácuo, que requer menor espaço de armazenamento. Os autores embalaram filé de salmão fresco com uma pequena quantidade de uma atmosfera composta por $100 \% \mathrm{CO}_{2}$ (volume gás/produto de 0,2/1) com a adição de uma solução de salmoura de diferentes compostos e obtiveram resultados positivos na preservação da qualidade microbiológica desse produto, durante 14 dias de armazenamento a $4{ }^{\circ} \mathrm{C}$.

Apenas os peixes, crustáceos e moluscos da melhor qualidade podem beneficiar-se das vantagens de um maior período de vida útil, conseguido com essa técnica de embalagem. As vantagens também dependem de cada espécie, do seu teor em gordura, da sua carga microbiana inicial, da mistura de gases da atmosfera e da temperatura utilizada no armazenamento.

\section{Conclusão}

Para a indústria de alimentos, a maior vida útil dos produtos significa menores perdas e possibilidade de um melhor planejamento da produção, dos estoques e da logística. A utilização de embalagem com atmosfera modificada, por atender uma preferência do consumidor por praticidade, garante também vantagens para os produtores e distribuidores no nível dos custos, da distribuição, do armazenamento e da vida útil. No entanto, o êxito dessa embalagem depende da qualidade inicial do produto, que está intimamente relacionada com: as boas práticas de higiene durante todo o percurso do produto; a composição da atmosfera adicionada e a proporção volume de gás/produto que é utilizada; o controle restrito da temperatura durante toda a vida útil, pois esta influencia o desenvolvimento microbiano e a solubilidade dos gases no alimento; a adequação dos materiais de embalagem às características do produto; o equipamento de embalagem, e o controle de qualidade integral e sistemático do processo de produção, distribuição e armazenamento.

Existem ainda algumas questões relacionadas com a logística envolvida na produção e na preservação desses produtos, essencialmente na cadeia de distribuição e de comercialização, na qual a manutenção da cadeia de frio é essencial. A utilização das novas embalagens ativas e inteligentes poderá ser a resposta para um maior e melhor controle desse fator. No entanto, estas ainda apresentam um custo demasiado elevado para serem utilizadas de forma corrente na venda de produtos embalados. O desenvolvimento de novos indicadores tempo/temperatura, mais eficientes e com menor custo, e de novos expositores frigoríficos com uma melhor manutenção da temperatura para os supermercados é essencial para o futuro e a qualidade dos alimentos MP em MAP.

\section{Referências}

AHVENAINEN, R. Ready-to-Use Fruit and Vegetables. Dublin: Teagasc (The National Food Centre), 2000. 16 p. Flair-Flow Europe Technical Manual F-FE 376A/00.

ALLENDE, A.; MCEVOY, J. L.; LUO, Y.; ARTES, F.; WANG, C. Y. Effectiveness of two-sided UV-C treatments in inhibiting natural microflora and extending the shelf-life of minimally processed "Red Oak Leaf" lettuce. Food Microbiology, London, v. 23, n. 3, p. 241-249, 2006. http://dx. doi.org/10.1016/j.fm.2005.04.009

ANTONIEWSKI, M. N.; BARRINGER, S. A.; KNIPE, C. L.; ZERB, H. N. Effect of a Gelatin Coating on the Shelf Life of Fresh Meat. Journal of Food Science, Chicago, v. 72, n. 6, p. E382-E387, 2007. http://dx.doi.org/10.1111/j.1750-3841.2007.00430.x

AYMERICH, T.; PICOUET, P. A.; MONFORT, J. M. Decontamination technologies for meat products. Meat Science, Essex, v. 78, n. 1-2, p. 114-129, 2008. http://dx.doi.org/10.1016/j. meatsci.2007.07.007

BRANDENBURG, J. S.; ZAGORY, D. Modified and Controlled Atmosphere Packaging Technology and Applications. In: YAHIA, E. M. (Ed). Modified and Controlled Atmospheres for the Storage, Transportation, and Packaging of Horticultural Commodities, CRC Press, Boca Raton, cap 4, p. 74-94, 2009. 
Revisão: Alimentos frescos minimamente processados embalados em atmosfera modificada

SANTOS, J. S. e OLIVEIRA, M. B. P. P.

BUCKLEY, M.; COWAN, C.; MCCARTHY, M. The convenience food market in Great Britain: Convenience food lifestyle (CFL) segments. Appetite, London, v. 49, n. 3, p. 600- 617, 2007. http://dx.doi.org/10.1016/j.appet.2007.03.226

CHOULIARA, E.; BADEKA, A.; SAVVAIDIS, I.; KONTOMINAS, M. G. Combined effect of irradiation and modified atmosphere packaging on shelf-life extension of chicken breast meat: microbiological, chemical and sensory changes. European Food Research and Technology, Berlin/Heidelberg, v. 226, n. 4, p. 877-888, 2008. http://dx.doi.org/10.1007/s00217-007-0610-3

CHUA, D.; GOH, K.; SAFTNER, R. A.; BHAGWAT, A. A. Fresh-cut lettuce in modified atmosphere packages stored at improper temperatures supports enterohemorrhagic E. coli isolates to survive gastric acid challenge. Journal of Food Science, Chicago, v. 73, n. 3, M148- M153, 2008. http://dx.doi. org/10.1111/j.1750-3841.2008.00698.x

CUTTER, C. N. Opportunities for bio-based packaging technologies to improve the quality and safety of fresh and further processed muscle foods. Meat Science, Essex, v. 74, n. 1, p. 131-142, 2006. http://dx.doi.org/10.1016/j.meatsci.2006.04.023

DALGAARD, P.; GRAM, L. HUSS, H. H. Spoilage and shelflife of cod fillets packed in vacuum or modified atmospheres. International Journal of Food Microbiology, Amsterdam, v. 19, n. 4, p. 283-294, 1993. http://dx.doi.org/10.1016/01681605(93)90020-H

EILERT, S. J. New packaging technologies for the 21st century. Meat Science, Essex, v. 71, n. 1, p. 122-127, 2005. http://dx. doi. org/10.1016/j.meatsci.2005.04.003

EUROPEAN COMMISSION. Health \& Consumer Protection Directorate-General. Opinion of the Scientific Committee on Food on the use of carbon monoxide as component of packaging gases in modified atmosphere packaging for fresh meat. Bruxelas, 2001 p. 1-9.

FELLOWS, P. Introduction In: FELLOWS, P. (Ed.). Food Processing Technology Principles and Practice. 2. ed. Cambridge: Woodhead publishing, 2000. cap. 1, p. 1-4.

FRANCIS, G. A.; O'BEIRNE, D. Effects of type, package atmosphere and storage temperature on growth and survival of Escherichia coli O157:H7 and Listeria monocytogenes. Journal of Industrial Microbiology and Biotechnology, Hampshire, v. 27, n. 2, p. 111-116, 2001. http://dx.doi.org/10.1038/ sj.jim. 7000094

GRANADO-LORENCIO, F.; OLMEDILLA-ALONSO, B.; HERRERO-BARBUDO, C. C.; ANCOS, B.; MARTÍNEZ, J. M.; PÉREZ-SACRISTÁN, B.; BLANCO-NAVARRO, I. Modifiedatmosphere packaging (MAP) does not affect the bioavailability of tocopherols and carotenoids from broccoli in humans: A crossover study. Food Chemistry, Barking, v. 106, n. 3, p. 1070- 1076, 2008. http://dx.doi.org/10.1016/j.foodchem.2007.07.038

GOULAS, A. E.; KONTOMINAS, M. G. Combined effect of light salting, modified atmosphere packaging and oregano essential oil on the shelf-life of sea bream (Sparus aurata): Biochemical and sensory attributes. Food Chemistry, Barking, v. 100, n. 1, p. 287-296, 2007. http://dx.doi.org/10.1016/j. foodchem.2005.09.045

HANSEN, A. A.; HOY, M.; PETTERSEN M. K. Prediction of Optimal $\mathrm{CO}_{2}$ Emitter Capacity Developed for Modified Atmosphere Packaging of Fresh Salmon Fillets (Salmo salar L.) Packaging Technology Science, Malden, v. 22, n. 4, p. 199-208, 2008. http://dx.doi.org/10.1002/pts.843

hANSEN, A. A.; MORKORE, T.; RUDI, K.; OLSEN, E.; EIE, T. Quality Changes during Refrigerated Storage of MA-Packaged Pre-rigor Fillets of Farmed Atlantic Cod (Gadus morhua L.) Using Traditional MAP, $\mathrm{CO}_{2}$ Emitter, and Vacuum. Journal of Food Science: Food Microbiology and Safety, Malden, v. 72 , n. 9, p. m423-m430, 2007. http://dx.doi.org/10.1111/j.17503841.2007.00561.x

HAUGAARD, V. K.; UDSEN, A.; MORTENSEN, G.; HØEGH, L.; PETERSEN, K.; MONAHAN, F. Potential Food Applications of Biobased Materials. An EU-Concerted Action Project. Starch/Stärke, Weinheim, v. 53, n. 5, p. 189-200, 2001. http://dx.doi.org/10.1002/1521-379X(200105)53:5<189::AIDSTAR189>3.0.CO;2-3

HAUGAARD, V. K.; MORTENSEN, G. Biobased food packaging. In: MATTSON, B.; SONNESON, U. (Eds.). Environmentally Friendly Food Processing. Cambridge: Woodhead publishing, 2003. cap. 11, p 170-193.

HOVDA, M. B.; SIVERTSVIK, M.; LUNESTAD, B. T.; LORENTZEN, G.; ROSNES, J. T. Characterisation of the dominant bacterial population in modified atmosphere packaged farmed halibut (Hippoglossus hippoglossus) based on 16S rDNA-DGGE. Food Microbiology, London, v. 24, n. 4, p. 362-371, 2007. http:// dx.doi.org/10.1016/j.fm.2006.07.018

HUSS, H. H. (Ed) Quality and Quality Changes in Fresh Fish. Rome: FAO, 1995. 150 p. (FAO Fish. Tech. Pap., n. 348).

KADER, A. Effects on Nutritional Quality. In YAHIA, E. M. (Ed). Modified and Controlled Atmospheres for the Storage, Transportation, and Packaging of Horticultural Commodities. Boca Raton: CRC Press, 2009. cap 6, p. 11-118.

KADER, A. A.; WATKINS, C. Modified Atmosphere PackagingToward 2000 and Beyond. HorTechonology, Alexandria, v. 10, n. 3, p. 483-486, 2000.

KORHONEN, H. Technology options for new nutritional concepts. International Journal of Dairy Technology, Huntingdon, v. 55, n. 2, p. 79-88, 2002. http://dx.doi.org/10.1046/j.14710307.2002.00050.x

LEE, S. K.; KADER, A. A. Preharvest and postharvest factors influencing vitamin $\mathrm{C}$ content of horticultural crops. Postharvest Biology and Technology, Amsterdam, v. 20, n. 3, p. 207-220, 2000. http://dx.doi.org/10.1016/S0925-5214(00)00133-2

LEISTNER, L.; GORRIS, L. G. M. Food preservation by hurdle technology. Trends in Food Science \& Technology, Cambridge, 
Revisão: Alimentos frescos minimamente processados embalados em atmosfera modificada SANTOS, J. S. E OLIVEIRA, M. B. P. P.

v. 6, n. 2, p. 41-46, 1995. http://dx.doi.org/10.1016/S09242244(00)88941-4

LOPEZ-RUBIO, A. GAVARA, R.; LAGARON, J. M. Bioactive packaging: turning foods into healthier foods through biomaterials. Trends in Food Science \& Technology, Cambridge, v. 17, n. 10, p. 567-575, 2006. http://dx.doi. org/10.1016/j.tifs.2006.04.012

MANCINI, R. A.; SUMAN, S. P.; KONDA, M. K. R.; RAMANATHAN, R. Effect of carbon monoxide packaging and lactate enhancement on the color stability of beef steaks stored at $1 \mathrm{C}$ for 9 days. Meat Science, Essex, v. 81, n. 1, p. 71- 76, 2009. http://dx.doi. org/10.1016/j.meatsci.2008.06.021

MANGARAJ, S.; GOSWAMI, T.K.; MAHAJAN, V. Applications of Plastic Films for Modified Atmosphere Packaging of Fruits and Vegetables: A Review. Food Engineering Reviews, New York, v. 1, n. 2, p. 133 - 158, 2009. http://dx.doi.org/10.1007/ s12393-009-9007-3

MARRERO, A, KADER, A. A. Optimal temperature and modified atmosphere for keeping quality of fresh-cut pineapples. Postharvest Biology and Technology, Amsterdam, v. 39, n. 2, p. 163-168, 2006. http://dx.doi.org/10.1016/j. postharvbio.2005.10.017

MARTÍNEZ-FERRER, M.; HARPER. C.; PÉREZ-MUÑOZ, F.; CHAPARRO, M. Modified Atmosphere Packaging of Minimally Processed Mango and Pineapple Fruits. Journal of Food Science, Chicago, v. 67, n. 9, p. 3365-3371, 2002. http://dx.doi. org/10.1111/j.1365-2621.2002.tb09592.x

MCMILLIN, K. W. Where is MAP Going? A review and future potential of modified atmosphere packaging for meat. Meat Science, Essex , v. 8, n. 1, p. 43- 65, 2008. http://dx.doi. org/10.1016/j.meatsci.2008.05.028

MENDES, R.; GONÇALVES, A. Effect of soluble $\mathrm{CO}_{2}$ stabilisation and vacuum packaging in the shelf life of farmed sea bream and sea bass fillets. International Journal of Food Science and Technology, Oxford, v. 43, n. 9, p. 1678-1687, 2008. http:// dx.doi.org/10.1111/j.1365-2621.2008.01737.x

MEYER, A. S.; SUHR, K. I.; NIELSEN, P.; LYNGBY, HOLM, F. Natural food preservatives. In: OHLSSON T.; BENGTSSON, N. (Ed.). Minimal processing technologies in the food industry, Cambridge, Woodhead publishing, 2002, cap. 6, p. 124- 174.

ÓLAFSDÓTTIR, G.; MARTINSDÓTTIR, E.; OEHLENSCHLÄGER, J.; DALGAARD, P.; JENSEN, B.; UNDELAND, I.; MACKIE, I. M.; HENEHEN, G.; NIELSEN, J.; NILSEN, H. Methods to evaluate fish freshness in research and industry. Trends in Food Science \& Technology, Cambridge, v. 8, n. 8, p. 258-265, 1997. http:// dx.doi.org/10.1016/S0924-2244(97)01049-2

ORGANISATION FOR ECONOMIC COOPERATION AND DEVELOPMENT - OECD, FOOD AND AGRICULTURE ORGANIZATION OF THE UNITED NATIONS - FAO. Agricultural Outlook 2008-2017. Paris: OECD Publications, 2008. 5 p.
ÖZOGUL, F.; POLAT, A.; ÖZOGUL, Y. The effects of modified atmosphere packaging and vacuum packaging on chemical, sensory and microbiological changes of sardines (Sardina pilchardus). Food Chemistry, Barking, v. 85, n. 1, p. 49-57, 2004. http://dx.doi.org/10.1016/j.foodchem.2003.05.006

PASTORIZA, L.; CABO, M. L.; BERNÁRDEZ, M.; SAMPEDRO, G.; HERRERA, J. J. R. Combined effects of modified atmosphere packaging and lauric acid on the stability of pre-cooked fish products during refrigerated storage. European Food Research and Technology, Berlin, v. 215, n. 3, p. 189-193, 2002. http:// dx.doi.org/10.1007/s00217-002-0557-3

PAUL, D. R.; CLARKE, R. Modeling of modified atmosphere packaging based on designs with a membrane and perforations. Journal of Membrane Science, Amsterdam, v. 208, n. 1-2, p. 269-283, 2002. http://dx.doi.org/10.1016/S03767388(02)00303-4

PAULSEN, P.; SMULDERS, F. J. M. Combining Natural Antimicrobial Systems with other Preservation Techniques: the Case of Meat. In: ZEUTHEN, P.; BOGH-SORENSEN, L. (Eds.). Food Preservation Techniques. Cambridge: Woodhead publishing, 2003. cap. 5.

PHILIPS, C. A. Review: Modified Atmosphere Packaging and its effects on the microbiological quality and safety of produce. International Journal of Food Science and Technology, Oxford, v. 31, n. 6, p. 463-479, 1996. http://dx.doi.org/10.1046/ j.1365-2621.1996.00369.x

POLI, B. M. Quality and certification of fishery products from both capture and farming in the same market place. In: CATAUDELLA, S.; MASSA, F.; CROSETTI, D. Interaction Between Aquaculture and Capture Fisheries: a Methodogical Perspective. Rome: FAO, 2005. (Studies and Reviews, n. 78).

RAGAERT, P.; VERBEKE, W.; DEVLIEGHERE, F.; DEBEVERE, J. Consumer perception and choice of minimally processed vegetables and packaged fruits. Food Quality and Preference, Essex, v. 15, n. 3, p. 259-270, 2004. http://dx.doi.org/10.1016/ S0950-3293(03)00066-1

RAGAERT, P.; DEVLIEGHERE, F.; DEBEVERE, J. Role of microbiological and physiological spoilage mechanisms during storage of minimally processed vegetables. Postharvest Biology and Technology, Amsterdam, v. 44, n. 3, p. 185-194, 2007. http://dx.doi.org/10.1016/j.postharvbio.2007.01.001

RAJAMÄKI, T.; ALAKOMI, H-L.; RITVANEN, T.; SKYTTÄ, E.; SMOLANDER, M.; AHVENAINEN, R. Application of an electronic nose for quality assessment of modified atmosphere packaged poultry meat. Guildford, v.17, n. 1, p. 5 - 13, 2006. http://dx.doi. org/10.1016/j.foodcont.2004.08.002

REDDY, N. R.; SOLOMON, H. M.; RHODEHAMEL, E. J. Comparison of Margin of Safety between Sensory Spoilage and onset of Clostrium Botulinum Toxin Development During Storage of Modified Atmosphere (MA)-Packaged Fresh Marine Cod Fillets with MA-Packaged Aquacultured Fish Fillets. Journal 
Revisão: Alimentos frescos minimamente processados embalados em atmosfera modificada

SANTOS, J. S. e OLIVEIRA, M. B. P. P.

of Food Safety, Westport, v. 19, n. 3, p. 171-18, 1999. http:// dx.doi.org/10.1111/j.1745-4565.1999.tb00243.x

REGENSTEIN, J. M. Use of Modified Atmosphere Packaging to Extend the Shelf Life of Fresh Fish: A Critical Look from a Historical Perspective. In: OTWELL, W. S.; KRISTINSSON, H. G.; BALABAN, M. O. (Eds). Modified Atmospheric Processing and Packaging of Fish: Filtered Smokes, Carbon Monoxide, and Reduced Oxygen Packaging. Ames: Blackwell Publishing, 2006. cap. 10, p. 142-163

ROKKA, M.; EEROLA, S.; SMOLANDER, M.; ALAKOMI, H.; AHVENAINEN, R. Monitoring of the quality of modified atmosphere packaged broiler chicken cuts stored in different temperature conditions B. Biogenic amines as quality-indicating metabolites. Food Control, Guildford, v. 15, n. 8, p. 601-607, 2004. http://dx.doi.org/10.1016/j.foodcont.2003.10.002

ROSNES, J. T.; SIVERTSVIK, M.; SKARA, T. Combining MAP with other preservation techniques. In: AHVENAINEN, R. (Ed). Novel food Packaging Techniques. Boca Raton: CRC Press, 2003. cap. 14

ROTABAKK, B. T.; BIRKELAND, S.; JEKSRUD, W. K.; SIVERTSVIK, $M$. Effect of modified atmosphere packaging and soluble gas stabilization on the shelf life of skinless chicken breast fillets. Journal of Food Science, Chicago, v. 71, n. 2, p. S124-S131, 2006. http://dx.doi.org/10.1111/j.1365-2621.2006.tb08915.x

SCHIRMER, B. C.; HEIBERG, R.; EIE, T.; MØRETR $\varnothing$, T.; MAUGESTEN, T.; CARLEHØG, M.; LANGSRUD, S. A novel packaging method with a dissolving $\mathrm{CO} 2$ headspace combined with organic acids prolongs the shelf life of fresh salmon. International Journal of Food Microbiology, Amsterdam, v. 133, n. 1-2, p. 154-160, 2009. http://dx.doi.org/10.1016/j. ijfoodmicro.2009.05.015

SEIDEMAN, S. C.; DURLAND, P. R. The Utilization of Modified Gas Atmosphere Packaging for Fresh Meat: a review. Journal of Food Quality, Westport, v. 6, n. 3, p. 239-252, 1984. http:// dx.doi.org/10.1111/j.1745-4557.1984.tb00827.x

SEYFERT, M.; MANCINI, R. A.; HUNT, M. C.; TANG. J.; FAUSTMAN, C. Influence of carbon monoxide in package atmospheres containing oxygen on colour, reducing activity, and oxygen consumption of five bovine muscles. Meat Science, Essex, v. 75, n. 3, p. 432-442, 2007. http://dx.doi.org/10.1016/j. meatsci.2006.08.007

SIVERTSVIK, M.; ROSNES, J. T.; BERGSLIEN, H. Modified atmosphere packaging. In: OHLSSON, T.; BENGTSSON, N. (Eds.). Minimal Processing Technologies in the Food Industry. Cambridge: Woodhead publishing, 2002a. cap. 4, p 61- 87.

SIVERTSVIK, M.; JEKSRUD, W. K.; ROSNES, J. T. A review of modified atmosphere packaging of fish and fishery productssignificance of microbial growth, activities and safety. International Journal of Food Science and Technology, Oxford, v. 37, n. 2, p. 107-127, 2002b. http://dx.doi.org/10.1046/ j.1365-2621.2002.00548.x
SIVERTSVIK, M.; ROSNES, J.T.; KLEIBERG, G.H. Effect of Modified Atmosphere Packaging and Superchilled Storage on the Microbial and Sensory Quality of Atlantic Salmon (Salmo salar) Fillets. Journal of Food Science, Chicago, v. 68, p. 1467 - 1468, 2003. http://dx.doi.org/10.1111/j.1365-2621.2003. tb09668.x

SKINNER, G. E.; REDDY, N. R. Hazards Associated with Clostridium botulinum in Modified Atmosphere Packaged Fresh Fish and Fishery Products. In: OTWELL, W. S.; KRISTINSSON, H. G.; BALABAN, M. O. (Eds.). Modified Atmospheric Processing and Packaging of Fish: Filtered Smokes, Carbon Monoxide, and Reduced Oxygen Packaging. Blackwell Publishing, 2006. cap. 11, p 163-192.

TUDELA, J. A.; ESPÍN, J. C.; GIL, M. I. Vitamin C retention in fresh-cut potatoes. Postharvest Biology and Technology, Amsterdam, v. 26, n. 1, p. 75-84, 2002. http://dx.doi.org/10.1016/ S0925-5214(02)00002-9

VAIKOUSI, H.; BILIADERIS, C. G.; KOUTSOUMANIS, K. P. Applicability of a microbial Time Temperature Indicator (TTI) for monitoring spoilage of modified atmosphere packed minced. International Journal Food Microbiology, Amsterdam, v. 133, n. 3, p. 272- 278, 2009. http://dx.doi.org/10.1016/j. ijfoodmicro.2009.05.030

WALSH, H. M.; KERRY, J. P. Meat packaging. In: KERRY, J.; KERRY, J.; LEDWARD, D. (Eds), Meat processing: Improving quality. Cambridge, UK: Woodhead publishing, 2002. cap 20.

WANG, T.; SVEINSDÓTTIR, K.; MAGNÚSSON, H.; MARTINSDÓTTIR, E. Combined Application of Modified Atmosphere Packaging and Superchilled Storage to Extend the Shelf Life of Fresh Cod (Gadus morhua) Loins. Journal of Food Science, Chicago, v. 73, n. 1, p. s11-s19, 2008. http://dx.doi. org/10.1111/j.1750-3841.2007.00590.x

YAM, K. L.; TAKHISTOV, P. T.; MILTZ, J. Intelligent Packaging: Concepts and Applications. Journal of Food Science, Chicago, v. 70, n. 1, p. R1-R10, 2005. http://dx.doi. org/10.1111/j.1365-2621.2005.tb09052.x

YUAN, J. T. C. Modified Atmosphere Packaging for Shelf-Life Extension. In: NOVAK, J. S.; SAPERS, G. M.; JUNEJA, V. K. (Eds.). Microbial Safety of Minimally Processed Foods. Boca Raton: CRC Press, 2003. cap. 10, p. 205-220.

ZEUTHEN, P. Safety criteria for minimally processed foods. In: OHLSSON, T.; BENGTSSON, N. (Eds.). Minimal Processing Technologies in the Food Industry. Cambridge: Woodhead publishing, cap. 8, p. 196-219, 2002. 